\title{
SISTEM PAKAR DIAGNOSA 33 MACAM PENYAKIT KULIT DAN KELAMIN DENGAN METODE FUZZY INFERENCE TSUKAMOTO
}

\author{
Alfian Fadli ${ }^{1}$, Ariadi Retno Tri Hayati Ririd ${ }^{2}$ \\ ${ }^{1}$ Teknik Informatika, Teknologi Informasi, Politeknik Negeri Malang \\ ${ }^{1}$ alfian_fadli99@yahoo.com, ${ }^{2}$ faniri4education@gmail.com
}

\begin{abstract}
Abstrak
Dalam dunia kedokteran kita menjumpai berbagai macam penyakit. Seorang dokter berperan sebagai seorang ahli yang memberikan diagnosa kepada pasien mengenai penyakit yang diderita berdasarkan keluhan atau gejala-gejala yang diderita oleh pasien. Masalah penentuan tingkat resiko penyakit sangat berhubungan dengan Clinical Decision Support System (CDSS).CDSS adalah sistem yang dirancang untuk membantu para pekerja klinis dalam mengambil keputusan. Dengan logika fuzzy, proses diagnosa penyakit kulit dan kelamin dapat dianalisa dengan Fuzzy Inference System dengan metode Tsukamoto. Input yang dibutuhkan adalah gejala-gejala yang dialami oleh seorang pasien yang mengalami yang diduga menderita penyakit kulit dan kelamin. Basis pengetahuan dibangun dengan menggunakan kaidah produksi (IF-THEN). Fire strength yang diperoleh pada setiap aturan fuzzy untuk setiap penyakit kulit dan kelamin pada basis pengetahuan, kemudian dikomposisikan dengan menggunakan rata-rata terbobot. Hasil dari rata-rata terbobot ini merupakan output tingkat resiko penyakit yang dialami oleh seorang pasien.
\end{abstract}

Kata kunci : Sistem Pakar 33 macam Penyakit kulit dan kelamin, Fuzzy inference tsukamoto, Clinical Decision Support system

\section{Pendahuluan}

Kesehatan kulit perlu diperhatikan karena kulit merupakan jaringan / organ yang paling vital serta cermin dari kesehatan dan kehidupan manusia. Fungsi kulit adalah melindungi tubuh terhadap serangan penyakit dari luar dan menjaga suhu tubuh agar tetap normal. Selain itu, kulit juga memiliki nilai estetika. Gangguan pada kulit sering terjadi karena berbagai faktor, antara lain : iklim, lingkungan tempat tinggal, kebiasaan hidup yang kurang sehat, alergi, dan ain-lain.

Hambatan-hambatan yang menyebabkan sulitnya melakukan konsultasi penyakit kulit sekarang ini dapat diatasi dengan adanya program komputer . Dalam hal ini sistem pakar dapat membantu pemecahan masalah terhadap penyakit kulit dengan di berikan nasihat kepada pemakai dan menemukan solusi terhadap berbagai permasalahan yang spesifik.

Tujuan pengembangan program ini bukan untuk menggantikan peran manusia, tetapi untuk mensubtitusikan pengetahuan manusia kedalam bentuk sistem agar dapat di gunakan oleh orang banyak.

Permasalahannya adalah bagaimana peneliti menyusun dan merancang suatu sistem pakar yang dapat digunakan untuk mendiagnosa suatu penyakit kulit berdasarkan gejala yang di alami user, memberi informasi penyebab penyakit, sehingga user dapat menemukan solusi atas permasalahan yang sedang dihadapi.
Dalam sistem pakar perhitungan ketidakpastian dapat dilakukan dengan beberapa metode, salah satunya adalah dengan logika Fuzzy. Logika Fuzzy merupakan suatu logika yang memiliki nilai kekaburan atau kesamaran antara benar atau salah. Namun berapa besar kebenaran dan kesalahan suatu tergantung pada bobot keanggotaan yang dimilikinya, logika Fuzzy memiliki derajat keanggotaan dalam rentang 0 atau 1. Logika Fuzzy adalah salah satu cara yang tepat untuk memetakan suatau ruang input ke dalam suatu ruang output, memiliki nilai kontinyu. Kelebihan dari logika Fuzzy adalah kemampuan dalam proses penalaran secara bahasa (linguistic reasoning ), sehingga dalam perancangannya tidak memerlukan persamaan matematik dari objek yang akan dikendalikan.

Dalam logika Fuzzy terdapat sistem inferensi Fuzzy yaitu sistem yang dapat melakukan penalaran dengan prinsip serupa seperti manusia melakukan penalaran dengan nalurinya. Sistem inferensi yang digunakan dalam penelitian ini adalah sistem inferensi metode Tsukamoto. Pada metode Tsukaomoto, setiap konsekuen pada aturan berbentuk IF-Then harus direpresentasikan dengan suatu himpunan Fuzzy dengan fungsi keanggotaan yang monoton. Sebagai hasilnya, output hasil interferensi dari tiap-tiap aturan diberikan secara tegas (crisp) berdasarkan $\alpha$-predikat (fire strength). Hasil akhirnya diperoleh dengan menggunakan rata-rata berbobot. 


\section{Sistem Pakar}

Definisi sederhana tentang sistem pakar merupakan salah satu sistem dalam komputer yang di rancang berdasarkan ilmu kepakaran sehingga dapat digunakan layaknya seseorang yang berkonsultasi dengan seorang pakar.

Sistem pakar adalah suatu sistem yang dirancang didepan komputer dengan cara meniru proses-proses pemikiran yang digunakan oleh seorang pakar untuk menyelesaikan masalahmasalah tertentu yang biasanya memerlukan keahlian seorang pakar (Turban, 1995).

Sistem pakar (Expert System) dibuat bertujuan untuk dapat menyelesaikan masalah yang cukup rumit yang sebenarnya hanya bisa diselesaikan oleh para ahli. Pembuatan sistem pakar bukan untuk menggantikan ahli itu sendiri melainkan dapat digunakan sebagai asisten yang sangat berpengalaman (Kusumadewi, 2003).

Sistem pakar adalah sistem perangkat lunak komputer yang menggunakan ilmu, fakta, dan teknik berpikir dalam pengambilan keputusan untuk menyelesaikan masalah-masalah yang biasanya hanya dapat diselesaikan oleh tenaga ahli dalam bidang yang bersangkutan (Marimin, 1992).

\section{a. Karateristik Sistem Pakar}

- Batasan untuk mencakup ruang lingkup tertentu

- Penalaran terhadap data yang tidak pasti.

- Proses pengembangan dapat dijalankan secara bertahap.

- Mekanisme inferensi terhadap basis pengetahuan (knowledge-based) dapat dibedakan.

- Output yang akan dihasilkan berupa saran pemecahan masalah.

- Pengetahuan secara umum berdasarkan kaidah (rule-based)

- Sistem mampu mengembangkan kaidah secara searah yang disesuaikan tuntunan oleh interaksi pemakai

\section{b. Manfaat Sistem Pakar}

- Solusi yang akan dihasilkan baik karena nasehat yang konsisten dan mengurangi kesalahan.

- Dapat menangkap kepakaran yang sangat terbatas.

- Memberikan akses pengetahuan yang mudah.

- Konsisten untuk melihat secara rinci dan tidak melewatkan informasi sedikitpun untuk memberikan solusi yang potensial

- Peningkatan terhadap kemampuan problem solving, karena mengambil sumber pengetahuan dari banyak pakar

\section{Konsep Fuzzy}

Konsep fuzzy logic yang sangat sistematis pertama kali diusulkan oleh Lutfi A. Zadeh, seorang professor bidang ilmu komputer dari Universitas
California, Amerika Serikat. Profesor Zadeh mempublikasikan makalah atau paper pertama yang membahas fuzzy set pada bulan Juni 1965. Beberapa tahun setelah publikasi tersebut, tepatnya pada tahun 1975-an, para ilmuwan Jepang berhasil mengaplikasikan konsep fuzzy ke dalam berbagai peralatan elektronik maupun proses produksi dalam industri.

Sebagai contoh konsep diatas usia manusia (merupakan contoh dari linguistik), yang dapat bernilai tua, muda, atau setengah baya yang sulit dilihat batasan-batasannya. Dengan menggunakan sistem komputer konvensional tentu saja sulit untuk mengolah variabel-variabel tersebut, maka munculah konsep fuzzy.

Penentuan tentang batasan tentang usia atau hal-hal lain yang bersifat kabur tergantung dari mereka yang menentukan, atau pembuat aturan fuzzy tersebut. Suatu misal batasan usia muda, usia muda dianggap antara 15-35 tahun, memang usia 10 tahun bukanlah usia muda. Konsep fuzzy menyajikan nilai keanggotaan suatu keadaan pada variabel tertentu dengan harga antara 0 dan 1 . Dengan demikian variabel yang sifatnya abstrak dan subyektif dapat dinyatakan secara numerik atau angka, sehingga mudah dilakukan pengolahan.

Menurut Subakti, Irfan dalam Khrisnahara (2009:9) Cara bekerja fuzzy memang harus menirukan cara kerja otak manusia dalam mengendalikan segala sesuatu. Dengan keunggulan tersebut maka diadakan usaha agar fuzzy menjadi sebuah pengendali dalam mengendalikan segala sesutu, dan ini terbukti lebih canggih dari pengendali apapun.

Ada beberapa alasan mengapa orang menggunakan logika fuzzy (Kusumadewi S, Purnomo H, 2010) antara lain:

- Konsep logika fuzzy mudah dimengerti. Konsep matematis yang mendasari penalaran fuzzy sangat sederhana dan mudah dimengerti.

- Logika fuzzy sangat fleksibel.

- Logika fuzzy memiliki toleransi terhadap datadata yang tidak tepat.

- Logika fuzzy mampu memodelkan fungsi-fungsi nonlinear yang sangat kompleks.

- Logika fuzzy dapat membangun dan mengaplikasikan pengalaman-pengalaman para pakar secara langsung tanpa harus melalui proses pelatihan.

- Logika fuzzy dapat bekerjasama dengan teknikteknik kendali secara konvensional.

- Logika fuzzy didasarkan pada bahasa alami.

\section{Metode Fuzzy Inference Tsukamoto}

Inferensi adalah proses penggabungan banyak aturan berdasarkan data yang tersedia. Komponen yang melakukan inferensi dalam sistem pakar disebut mesin inferensi. Menurut Sri Kusumadewi dan Sri Hartati (2006:34) sistem inferensi fuzzy merupakan 
suatu kerangka komputasi yang didasarkan pada teori himpunan fuzzy, aturan fuzzy yang berbentuk IFTHEN, dan penalaran fuzzy.

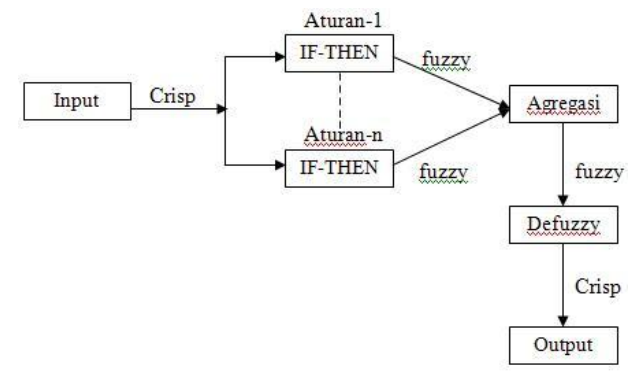

Gambar 1. Diagram Blok Sistem Inferensi Fuzzy

Sistem inferensi fuzzy menerima input crisp. Input ini kemudian dikirim ke basis pengetahuan yang berisi $\mathrm{n}$ aturan fuzzy dalam bentuk IF-THEN. Fire strength (nilai keanggotaan anteseden atau $\alpha$ ) akan dicari pada setiap aturan. Apabila aturan lebih dari satu, maka akan dilakukan agregasi semua aturan. Selanjutnya pada hasil agregasi akan dilakukan defuzzy untuk mendapatkan nilai crisp sebagai output sistem. Salah satu metode FIS yang dapat digunakan untuk pengambilan keputusan adalah metode Tsukamoto. Berikut ini adalah penjelasan mengenai metode FIS Tsukamoto.

Pada metode Tsukamoto, implikasi setiap aturan berbentuk implikasi "Sebab-Akibat"/Implikasi "Input-Output" dimana antara anteseden dan konsekuen harus ada hubungannya. Setiap aturan direpresentasikan menggunakan himpunanhimpunan fuzzy, dengan fungsi keanggotaan yang monoton. Kemudian untuk menentukan hasil tegas (Crisp Solution) digunakan rumus penegasan (defuzifikasi) yang disebut "Metode rata-rata terpusat" atau "Metode defuzifikasi rata-rata terpusat (Center Average Deffuzzyfier) (Setiadji, 2009: 200).

Misalkan ada 2 variabel input, Var-1 (x) dan Var-2(x), serta variabel output, Var-3(z), dimana Var1 terbagi atas 2 himpunan yaitu A1 dan A2. Var-2 terbagi atas 2 himpunan $\mathrm{B} 1$ dan $\mathrm{B} 2$, Var-3 juga terbagi atas 2 himpunan yaitu $\mathrm{C} 1$ dan $\mathrm{C} 2$ (C1 dan $\mathrm{C} 2$ harus monoton). Ada 2 aturan yang digunakan, yaitu:

[R1] IF ( $\mathrm{x}$ is A1) and (y is B2) THEN ( $\mathrm{z}$ is $\mathrm{C} 1$ )

[R2] IF ( $\mathrm{x}$ is A2) and (y is B1) THEN ( $\mathrm{z}$ is $\mathrm{C} 2$ )

\section{Proses Alur dari Sistem FIS Tsukamoto}

Gambar dibawah ini adalah alur dari sistem dengan menggunakan metode fuzzy inference tsukamoto.

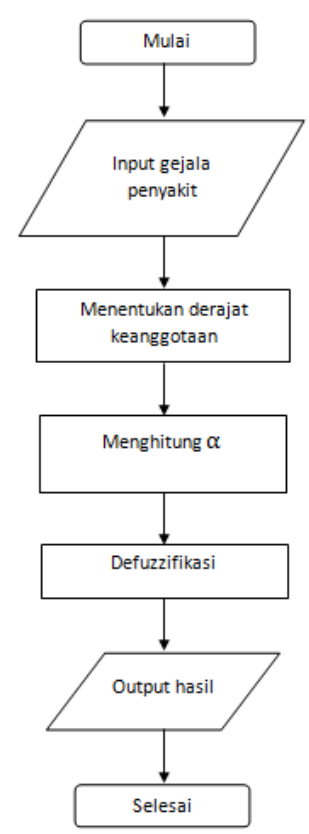

Gambar 2. Flowchart Logika FIS Tsukamoto

- Input gejala penyakit kulit dan kelamin

Dalam perancangan sistem pakar ini menggunakan inputan dari hasil pemeriksaan laboratorium. Hasil pemeriksaan tersebut merupakan variabel-variabel yang digunakan dalam penegakan diagnosis penyakit kulit dan kelamin yaitu merupakan gejala-gejala yang menyebabkan penyakit kulit dan kelamin.

\section{- Menentukan keanggotaan himpunan}

Setiap variabel sistem dalam himpunan fuzzy ditentukan derajat keanggotaannya $(\mu)$. Dimana derajat keanggotaan tersebut menjadi nilai dalam himpunan fuzzy.

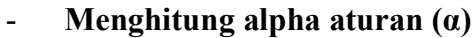

Variabel-variabel yang telah dimasukkan dalam himpunan fuzzy, dibentuk aturan-aturan yang diperoleh dengan mengkombinasikan setiap variabel dengan variabel yang satu dengan atribut lingusitiknya masing-masing. Aturan-aturan yang telah diperoleh akan dihitung nilai predikat aturannya dengan proses implikasi. Dalam metode Fuzzy Tsukamoto proses implikasi dilakukan dengan operasi AND. Predikat aturan tersebut diperoleh dengan mengambil nilai minimum dari derajat keanggotaan variabel yang satu dengan variabel yang lain, yang telah dikombinasikan dalam aturan yang telah ditentukan sebelumnya.

\section{- Defuzzifikasi}

Setelah mendapatkan nilai $\alpha$ kemudian disubstitusikan pada fungsi keanggotaan himpunan sesuai aturan fuzzy untuk memperoleh nilai z (nilai perkiraan produksi. Kemudian 
lakukan perkalian nilai $\alpha$ dengan nilai $\mathrm{z}$ yang disesuaikan berdasarkan rule yang ada. Metode defuzifikasi yang digunakan dalam metode Tsukamoto adalah metode defuzifikasi rata-rata terpusat (Center Average Defuzzyfier) :

$$
Z=\frac{\Sigma(\alpha * z)}{\Sigma \alpha}
$$

\section{- Hasil proses}

Setelah melewati rangkaian proses, maka akan didapatkan hasil proses.

\section{WBS (Work Breakdown Structure)}

Berikut ini adalah perancangan sistem WBS sebagai gambaran dalam menjelaskan proses berjalannya sistem :

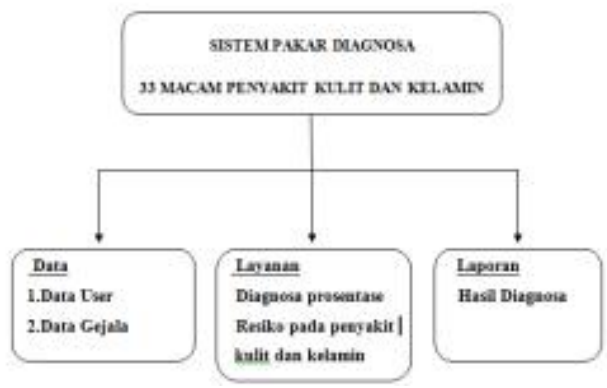

Gambar 3. WBS dar system pakar

WBS (Work Breakdown Structure) Merupakan gambaran struktur pembuatan system. WBS terdiri dari 3 (tiga) bagian yaitu Data, layanan, laporan. Data merupakan komponen utama yang digunakan untuk membangun suatu system, meliputi data user dan data gejala. Layanan dalam sistem ini adalah sebagai media diagnose awal kemungkinan tingkat prosentase penyakit kulit dan kelamin yang dialami user. Untuk laporan, system ini memberikan laporan berupa hasil diagnose penyakit.

\section{Tampilan Antarmuka}

Berikut adalah contoh gambar dari sistem pakar berupa hasil analisa, jadi setelah memilih beberapa gejala yang diderita oleh pasien maka hasil output akhir akan menampilkan halamn ini yaitu inti dari sistem ini, pasien akan memperoleh hasil penyakit yang diderita dan juga prosentase kemungkinan yang telah dihitung oleh sistem.

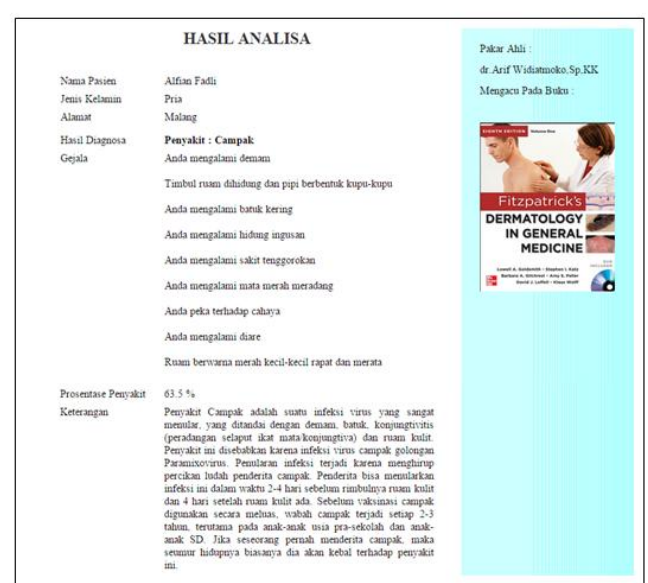

Gambar 4. Tampilan Hasil Analisa Diagnosa

\section{Hasil Pengujian}

Proses Perhitungan Manual

Pada proses fuzzyfikasi nilai numerik akan diubah menjadi variabel linguistik yang memiliki nilai linguistik. Nilai linguistik ini nantinya akan digunakan pada proses inferensi. Untuk memperoleh derajat keanggotaan dari nilai linguistik pada masingmasing input sistem menggunakan fungsi keanggotaan sebagai berikut :

$$
\begin{aligned}
& \mu_{\text {VeryLow }}[x]\left\{\begin{array}{cc}
1, & x=0 \\
\frac{4-x}{4}, & 0<x<4 \\
0, & x \geq 4
\end{array}\right. \\
& \mu_{\text {Low }}[x]\left\{\begin{aligned}
0, & x \leq 0 \\
\frac{x-0}{4}, & 0<x<4 \\
1, & x=4 \\
\frac{8-x}{4,} & 4<x<8 \\
0, & x \geq 8
\end{aligned}\right. \\
& \mu_{\text {Middle }}[x]\left\{\begin{aligned}
0, & x \leq 4 \\
\frac{x-4}{4}, & 4<x<8 \\
1, & x=8 \\
\frac{12-x}{4}, & 8<x<12 \\
0, & x \geq 12
\end{aligned}\right. \\
& \mu_{\text {High }}[x]\left\{\begin{aligned}
0, & x \leq 8 \\
\frac{x-8}{4}, & 8<x<12 \\
1, & x=12 \\
\frac{16-x}{4}, & 12<x<16 \\
0, & x \geq 16
\end{aligned}\right. \\
& \mu_{\text {VeryHigh }}[x]\left\{\begin{aligned}
0, & x & \leq 12 \\
\frac{x-12}{4}, & 12 & <x<16 \\
1, & x & \geq 16
\end{aligned}\right.
\end{aligned}
$$




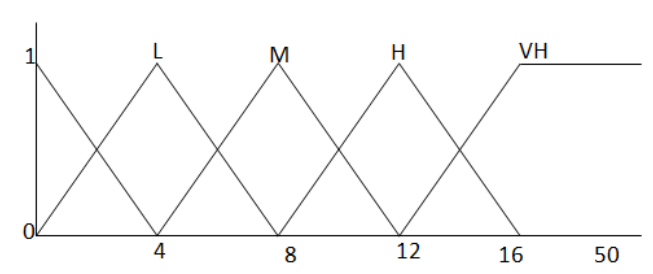

Gambar 4. Grafik Fungsi Derajat Keanggotaan

Menentukan Inputan Nilai dari Gejala

- Nyeri dan kekakuan : 4

- Nyeri otot, kelemahan otot : 12

- Demam tanpa diketahui penyebabnya : 15

- Merasa sangat lelah : 17

- Ruam dihidung dan pipi berbentuk kupu-kupu : 20

- Kesulitan berpikir masalah memori, kebingungan : 9

Perhitungan Mencari Nilai $\boldsymbol{\alpha}$ - predikat*zi

Tabel 1. Perhitungan Mencari nilai hasil

\begin{tabular}{|c|c|c|c|}
\hline No & $\alpha-$ predikat & zi & $\alpha$-predikat*zi \\
\hline 1 & 1 & 4 & 4 \\
\hline 2 & 1 & 12 & 12 \\
\hline 3 & 0,25 & 15 & 3,75 \\
\hline 4 & 1 & 17 & 17 \\
\hline 5 & 1 & 20 & 20 \\
\hline 6 & 0,75 & 9 & 6,75 \\
\hline
\end{tabular}

Proses Defuzzyfikasi

Diketahui :

$$
\begin{aligned}
& \alpha \text {-predikat } \quad=1 \\
& \mathrm{Zi}=20 \\
& Z *=\frac{\sum \alpha-\text { predikat } * \mathrm{Zi}}{\sum(\alpha-\text { predikat })} \\
& \mathrm{Z}^{*}=63,5 / 5=12,7
\end{aligned}
$$

Proses Hasil Output

Prosentase $=Z * /$ Jumlah variabel Keanggotaan $* 100$ $=12,7 / 16 * 100$

\begin{tabular}{|c|c|c|c|c|c|c|}
\hline No & \begin{tabular}{|l|l} 
Gejala \\
\end{tabular} & $\begin{array}{l}\text { Hasil } \\
\text { Pakar }\end{array}$ & \begin{tabular}{|l|} 
Hasil \\
Sistem
\end{tabular} & $\begin{array}{l}\text { Diagnosa } \\
\text { Pakar }\end{array}$ & \begin{tabular}{|l|} 
Diagnosa \\
Sistem
\end{tabular} & \begin{tabular}{|l} 
Hasil \\
pengujian
\end{tabular} \\
\hline 1. & $\begin{array}{l}\text { - Kulit terasa nyeri } \\
\text { - Otot terasa nyeri } \\
\text { - Anda mengalami demam } \\
\text { - Anda merasa sangat lelah } \\
\text { - Timbul ruam dihidung dan } \\
\text { pipi berbentuk kupu-kupu } \\
\text { - Anda kesulitan berpikir } \\
\text { masalah ingatan dan } \\
\text { merasa kebingungan } \\
\text { - Data Gambar Lupus }\end{array}$ & 70.625 & 70.625 & Lupus & \begin{tabular}{|l} 
Lupus \\
\end{tabular} & Sesuai \\
\hline 2 & $\begin{array}{l}\text { - Adanya rasa gatal } \\
\text { - Adanya iritasi pada kulit } \\
\text { - Kulit berdarah } \\
\text { - Timbul tahi lalat } \\
\text { - Kulit terasa nyeri } \\
\text { - Kulit menjadi luka dan } \\
\text { terjadi borok atau tukak } \\
\text { - Data Gambar Kanker Kulit }\end{array}$ & 69.408 & 69.408 & $\begin{array}{l}\text { Kanker } \\
\text { Kulit }\end{array}$ & $\begin{array}{l}\text { Kanker } \\
\text { Kulit }\end{array}$ & Sesuai \\
\hline
\end{tabular}

$=79,375 \%$

\section{Pengujian Akurasi}

Tabel 2. Pengujian Akurasi

\section{Kesimpulan}

Berdasarkan hasil analisis yang telah diteliti, metode fuzzy tsukamoto dapat membantu sistem dalam mendiagnosa seseorang terkena penyakit kulit dan kelamin. Sistem ini dapat digunakan oleh rumah sakit dan dokter spesialis untuk menghitung presentase kemungkinan pasien yang terkena penyakit kulit dan kelamin. User dapat mengetahui prosentase penyakitnya berdasarkan gejala-gejala yang diderita oleh pasien.

\section{Saran}

Sistem ini dapat dikembangkan dalam menentukan rules/aturan untuk melakukan validasi atau pengamatan terlebih dahulu ke rumah sakit atau dokter spesialis supaya rules yang dipakai lebih valid. Selain itu, disarankan untuk menambah fitur yang belum ada pada program, karena dalam program ini hanya sebatas presentase pasien yang terkena penyakit kulit dan kelamin.

Untuk pengguna program ini, khususnya pasien, jika sudah mengetahui status presentase kemungkinan terkena penyakit kulit dan kelamin diharapkan untuk melakukan penanganan lebih lanjut sehingga masih ada kemungkinan penyakit dapat disembuhkan.

\section{Daftar Pustaka}

Kusumadewi, Sri., Purnomo, Hari. 2004. "Aplikasi Logika Fuzzy Untuk Pendukumg Keputusan”.

Sri Kusumadewi, "Artificial Intelligence Teknik dan Aplikasinya," Graha Ilmu Yogyakarta.

Madcoms. 2011. "Aplikasi Web Database dengan Dreamweaver dan PHP - MYSQL".

Kusrini. 2006." Sistem Pakar Teori dan Aplikasi”. Yogyakarta: Penerbit Andi.

Arhami, M. 2005. “ Konsep Dasar Sistem Pakar. Jilid l'. Yogyakarta: Andi.

Abdurrahman, Ginanjar. 2011. "Penerapan Metode Tsukamoto (Logika Fuzzy) dalam Sistem Pendukung Keputusan untuk Menentukan Jumlah Produksi Barang Berdasarkan Data 
Persediaan dan Jumlah Permintaan". Program Studi Matematika, Fakultas Matematika dan Ilmu Pengetahuan Alam, Universitas Negeri Yogyakarta.

Maharani, Ayu. 2015 “Penyakit Kulit (Perawatan, Pencegahan, Pengobatan)" Pustaka Baru press, Yogyakarta
Fitzpatricks 2012 “ Dermatology in General medicine - Volume Eighth Edition” Penerbit Mc Graw Hill Medical Company.

Turban, Efraim. 2005." Decision Support System and Intelligent System". Yogyakarta:Andi. 